Journal of Applied Finance \& Banking, Vol. 11, No. 5, 2021, 45-67

ISSN: 1792-6580 (print version), 1792-6599(online)

https://doi.org/10.47260/jafb/1153

Scientific Press International Limited

\title{
Role of Digital Financial Services in Confronting Covid-19 Crisis in Bangladesh
}

\author{
Md. Johir Rayhan' ${ }^{1}$ and Md. Jahir Uddin ${ }^{2}$
}

\begin{abstract}
This study examines the impact of Digital Financial Services (DFSs) in confronting COVID-19 crisis in Bangladesh. It attempts to explore the magnitude of using DFSs along with the efficacy and difficulties of DFSs in coping with humanitarian emergency during COVID-19 pandemic. For analyzing the role of DFSs, the study collects primary data by carrying out a computerized questionnaire survey among 100 respondents. According to the field survey outcomes, DFSs are found useful as transactions can be done efficiently while maintaining social distance. Therefore, an increasing number of people are using DFSs for financial transactions during the pandemic. However, the survey outcomes also report that preferring DFSs over physical cash have many challenges such as data privacy concern, digital fraud, transaction limit problem, difficulty in cashing out and others. If these challenges are addressed properly, DFSs can play an important role in strengthening the resilience of populations during the crisis.
\end{abstract}

JEL classification numbers: G01.

Keywords: Digital Financial Services, COVID-19 Crisis, Humanitarian Emergency, Bangladesh.

1 Department of Banking and Insurance, University of Dhaka

2 Lecturer, Department of Gender and Development Studies, Begum Rokeya University, Rangpur.

Article Info: Received: May 30, 2021. Revised: June 15, 2021.

Published online: June 30, 2021. 


\section{Introduction}

The world is now experiencing a health catastrophe due to COVID-19 crisis, also known as coronavirus crisis. The World Health Organization (WHO) declared the coronavirus crisis as a pandemic On March 12, 2020, and later it has become a global pandemic affecting the population at a large scale worldwide. This is by large, one of the scariest pandemics which has resulted in significant social and economic instability across the globe. As a consequence of deadly infections of this virus, various state, regional and foreign approaches have been critical to resolve the imminent humanitarian emergencies. In this study, we will mainly focus on how DFSs are helpful in facing humanitarian emergencies during COVID-19 pandemic. The COVID-19 pandemic emerged in Bangladesh on March 8, 2020. Being a heavily inhabited developing nation in the Third World, the pandemic then started to escalate to a humanitarian catastrophe and still have been affecting the lives of thousands of people on a daily basis. The pandemic is badly affecting the livelihood of people in Bangladesh since a significant portion of the population is living below the poverty line and most of the people in the workforce are employed in the informal sector. Therefore, the impact of COVID-19 crisis on the economy of Bangladesh is huge because managing the health crisis while keeping the economy well-functioning is very difficult for the Government.

To accelerate the emergency responses to COVID-19 crisis, the distribution of cashbased benefits to the impacted community has drawn considerable global interest (Hussain, 2020). The COVID-19 is deemed to be the deadliest pandemic among reported pandemics in the past. The impact of this pandemic are apprehended to be continued for unknown time periods and can create famine afterwards.

Digital Financial Service (DFS) solutions, especially mobile money facility can play a great role in providing cash based assistance to the crisis affected populations. In a broad sense, DFSs can provide ATMs, debit cards, and other automated payment options that can be utilized to deliver financial services to the community while ensuring security, accountability, and transparency. Nevertheless, it is not without obstacles to ensure the efficacy of the usage of DFSs in facilitating emergency responses during COVID-19 crisis. Policy requirements, network infrastructure, and social constraints sometimes impede the effective use of DFSs in fulfilling its purposes. The utilization of the benefits and minimizing the challenges are expected to improve the efficacy of DFSs in confronting COVID-19 crisis in Bangladesh.

\subsection{Background and Rationale of the Study}

Humanitarian emergencies are the direct consequences of any event affecting health, safety, and well-being of the vulnerable section of the society. COVID-19 crisis is such an unprecedented phenomenon that is responsible for global humanitarian emergency. It will be continued until the spread of this infectious virus is completely regulated. The lives of the affected population are hazardous during this crisis as the virus is life-threatening and the economic consequences of this crisis are tied to 
deprivation. Many people have been unable to earn their livelihood during this crisis because the virus has caused the authority to shut down the cities to control the spreading of the virus. As a result, poor and marginalized people have been in need of daily necessities during the crisis. To deal with this complex emergency, immediate responses are necessary from both government and non-government organizations as well as from wealthy people who are capable of helping the vulnerable people temporarily. For confronting this crisis, both in kind transfer (food distribution programs) and cash transfer programs seem to be the immediate solutions especially for the third world countries (Hussain, 2020).

In Bangladesh, there is a recurrent humanitarian emergency in different parts of the country as a consequence of cyclones, floods, river depletion, and other calamities. Usually, the Ministry of Disaster Management and Relief takes the overall responsibility for coordinating the food distribution and cash sectioning program to the affected communities. In addition to the Government, there are other actors in the humanitarian ecosystem such as, private donors, Non-Governmental Organizations (NGOs) and humanitarian aid agencies that also run support programs for addressing the emergencies. Initially when coronavirus pandemic broke out in Bangladesh, food distribution program was an immediate response to assist the disadvantaged populations living below the poverty line. This program was initiated to enforce stringent lockdown and social distancing practices throughout the infected regions.

According to the Bangladesh Bureau of Statistics (BBS), at least 34 million people live below the poverty line and $85.1 \%$ people of the total workforce are employed in the informal sector in Bangladesh. Thus, considering the difficulties of vulnerable people in managing their livelihood during the crisis, the Government of Bangladesh has come out with a massive stimulus package to address the economic consequences of the crisis (Gomes, 2020). This stimulus package amounted to USD 8 billion or BDT 727 billion initially and among them 5.9 million USD or BDT 50 billion was approved to help the export-oriented industry. Later, the Government has announced additional packages for affected industries and vulnerable populations and thus, taking the total stimulus package past BDT 1.0 trillion. The total stimulus packages then have been amounted to almost 3.6\% of total GDP ("Bangladesh's Stimulus", 2020).

From the historical evidence it is found that the essence of assistance has switched from traditional commodity-based (in-kind) solutions to more cash-based strategies. DFSs are rapidly being used by the global humanitarian aid sector to support cashbased emergency response strategies. It is therefore can be considered to be the most preferred method of delivering financial aid and supplying the victim people with the ability to purchase their needs and also to sustain local economies. Since mobile money has emerged to be a popular tool for digital cash transfers, DFSs can be considered to be the fastest and most cost-effective medium of transferring financial assistance to the affected populations (Gomes, 2020).

Considering the COVID-19 pandemic, the way to deliver cash like benefits can be seen as relatively safer than transporting physical goods and dealing with hard cash. 
The method of transferring cash through digital means is supposed to ensure more control of government and aid agencies, transparency and accountability. On the other hand, for transferring cash benefits through DFSs, digital infrastructures are needed. Again, the literacy of using DFSs and legislative standards need to be ensured for successful distribution of funds to the disadvantaged and vulnerable citizens.

In Bangladesh, financial inclusion is a buzzword and DFSs are playing a key role in this respect. Being a densely populated developing country, still many residents are financially excluded and underserved. However, there are simple but strong innovations in the use of mobile phones in Bangladesh nowadays. Adopting these advantages, financial sector and digital operators are already moving fast to include the majority of the populations under financial services.

Financial services have long been used in crisis contexts to help vulnerable and excluded people in coping with shocks, minimizing risk exposures and stimulating economic activity. As COVID-19 crisis is predicted to affect the vulnerable populations and the economy for an unknown time period, there is a scope of research to investigate the role of DFSs in facing humanitarian crisis during the pandemic. In this purpose, the extent of using DFSs in confronting COVID-19 crisis needs to be explored. Also, the effectiveness and challenges of using DFSs in providing financial assistance to vulnerable people need to be properly identified and measured.

\section{Literature Review}

The novel coronavirus or simply COVID-19 emerged late in 2019. Consequently, this virus started to propagate globally and has been declared as global pandemic afterward. To fight against the virus, countries across the world have enforced strict stay-at-home measures and complete economic shut down in particular. Since the saving tendency or capability of saving among the middle income and poorest populations in developing nations are lower, the stringent measures taken against the spreading of the virus have negative consequences on these people.

In confronting the COVID-19 crisis, the stimulus packages from governments seem to be an immediate solution provided that there is suitable mechanism is in place for individuals and households to access the assistance. This is difficult in the case of lower-income countries where a huge majority of the population remains unbanked (Dewar, 2020). DFSs are the agreed option for the citizens in both industrialized and emerging economies in this new era of digitalization.

Digital financial services (DFS) refer to the means of digital access for using formal financial services by the underserved and disadvantaged population. Such services are supposed to be sustainable for the providers and affordable to the customers in terms of cost and responsible delivery to meet the needs of users. DFSs include three key components: a digital transactional platform, retail agents and a device which is most commonly a mobile phone used by both agents and customers to facilitate transactions (K-Mujeri and E-Azam, 2018). 
In a recent discussion, (Davidovic, Prady and Tourpe, 2020) show that many emerging and low-income countries cannot directly protect jobs during the crisis. So, they are enhancing direct support to households and individuals.

Gurung and Perlman (2018) have drawn some insights about cash-based assistance to crisis affected population. According to them, cash based assistance is the preferred and default method for helping vulnerable communities. Therefore, it can fulfill multiple goals such as providing the ability to purchase the goods and services the beneficiaries need most, distributing aid and giving necessary support to local economies, etc. They also have shared their opinion on using DFS solutions especially 'mobile money' to accelerate cash based assistance by humanitarian aid sector. They have defined 'mobile money 'as a popular tool for digital cash transfers. For humanitarian purposes, the aid agencies and supporting actors can provide cash vouchers for specific products or can directly transfer aid to the mobile accounts of eligible people. Besides, the mobile money can also be used to safeguard savings, receive remittances, and obtain credits.

Davidovic et al. (2020) also have discussed mobile money. In their discussion on 'Mobile payments help people during the pandemic', they have defined mobile money as an efficient means of providing large-scale cash transfer and also as a safer option in terms of maintaining social distancing practices. In addition, they have found that the ownership and the use of mobile phones are very high in emerging and developing economies. Therefore, the people from rural and remote areas can get easy access to the fund of government cash transfer programs. They can cash out money easily without having to travel a long distance, waiting in a queue and having a bank account in place.

There are other benefits of using DFSs in providing cash based assistance to crisis affected population. The DFS solutions are mainly fast, secure and cost-effective. It is relatively safer, transparent and reliable. But, the process in action is not without challenges. The limitations mainly cover the policy requirements, social barriers and network infrastructures. Hereafter, lack of digital and financial literacy can discourage people from using mobile money (Gurung and Perlman, 2018).

Besides, the mobile money transfer can be an expensive option if there is limited mobile coverage for people in rural and remote areas. Also, the access to money agents for exchanging mobile money for cash may not be easy. There are also risks of digital fraud and cybersecurity which shouldn't outweigh the benefits. The COVID-19 crisis has forced the Governments of many countries to address the constraints and to strengthen their mobile money ecosystem. A broad approach should be taken by the Governments that go beyond the technology (Davidovic et al., 2020).

In another study on the impact of DFSs in confronting crisis by El-Zoghbi, Chehade, McConaghy, and Soursourian (2017), they have found some evidences which show that financial services can play a positive role in facing crisis situations. They also have listed some researches where cash transfers are mentioned to have multiplier effects on economic activity and therefore, efficiency, security and amenity can be improved by digital delivery of cash transfer. In addition, they put more emphasis 
on payment infrastructure, sociocultural factors and regulatory framework for the positive outcome of cash transfers. According to them, lack of effective policies and crisis preparedness are the main barriers to the effective delivery options. The role of donors in supporting market players like injecting liquidity into local financial markets can help in crisis preparedness.

In Bangladesh, the financial sector is driven by the process of powerful innovations in the use of mobile phones and it is moving fast by the time being. Besides, the digital wallet, introduced as having electronic prepaid card with mobile banking facilities, are utilizing mobile phones, ATMs and other forms of e-banking facilities simultaneously. With the help of these kinds of innovations, transaction costs are reducing. Thus, it is becoming possible to use financial products and applications profitably to reach great number of people including the poor (K-Mujeri and EAzam, 2018).

DFSs are playing a great role in promoting financial inclusion in Bangladesh. In the present scenario of COVID-19 situation in Bangladesh, DFSs can help to confront COVID-19 crisis at a large extent. This kind of crisis situation is unique to the world and so to the Bangladesh as well. Therefore, there is lack of studies which has focused on how DFSs are helpful in confronting COVID-19 crisis. An empirical investigation on this topic can help to increase our understanding and knowledge. Thus, this study can be helpful to the concerned authority in taking decision on successfully implementing strategies for facing COVID-19 crisis. Also, the study will be helpful in conducting future researches in this area.

\section{Objectives and Question}

\subsection{Research Objectives}

This study covers a broad objective along with some specific objectives.

\subsubsection{General objectives}

To investigate the impact of DFSs in confronting COVID-19 crisis in Bangladesh.

\subsubsection{Specific Objectives}

To explore the extent of using DFSs during COVID-19 crisis in Bangladesh

To evaluate the effectiveness of DFSs in response to the COVID-19 crisis in Bangladesh.

To identify the challenges of DFSs in facing the emergency arises for COVID-19 pandemic in Bangladesh.

\subsection{Research Question}

This study tries to answer the question 'how helpful are digital financial services in confronting COVID-19 crisis in Bangladesh?' 


\section{Data and Method}

This is basically a survey-based study and a systematic review design approach has been followed in conducting the study. To conduct this research, we have used both primary and secondary data. The primary data were collected through carrying out a computerized questionnaire survey among respondents living in different areas over the country and involving in different occupations. In conducting the survey, we have followed convenience sampling technique with a sample size of 100. In the survey questionnaire, both open-ended and close-ended questions were included to collect opinion on the role of DFSs in confronting COVID-19 crisis. The secondary data have been accumulated from different articles published in blogs, websites and newspapers, Bangladesh Bank publication, reports etc.

The role of DFSs are measured on extent of using DFSs, dependency on DFSs for financial transactions during the pandemic, implications of cash assistance program through DFSs and benefits and challenges of using DFSs. For analyzing the data, a database system was followed where the raw data was inserted into the database system. A rigorous scrutiny of the data was undergone to ensure the validity of the data. Also, reliability analysis on the scaled data was conducted to ensure the internal consistency of the data. The study employs SPSS tool to analyze survey data. The tables and charts have been used to present the data.

\section{Analysis and Discussion}

\subsection{Analysis}

Among the respondents, we have male-female ratio of 69:31 which means $69 \%$ are male respondents and $31 \%$ are female respondents. The age of the respondents varies from 20 years to 65 years. Respondents are from different locations of the country, and they are also from different occupations such as, students, bankers, businessmen, teachers, government employees and other professions such as freelancers, entrepreneurs, research assistants, etc.

Based on the authors' survey data, there are some findings related to the study's objectives and they are presented in the following graphs:

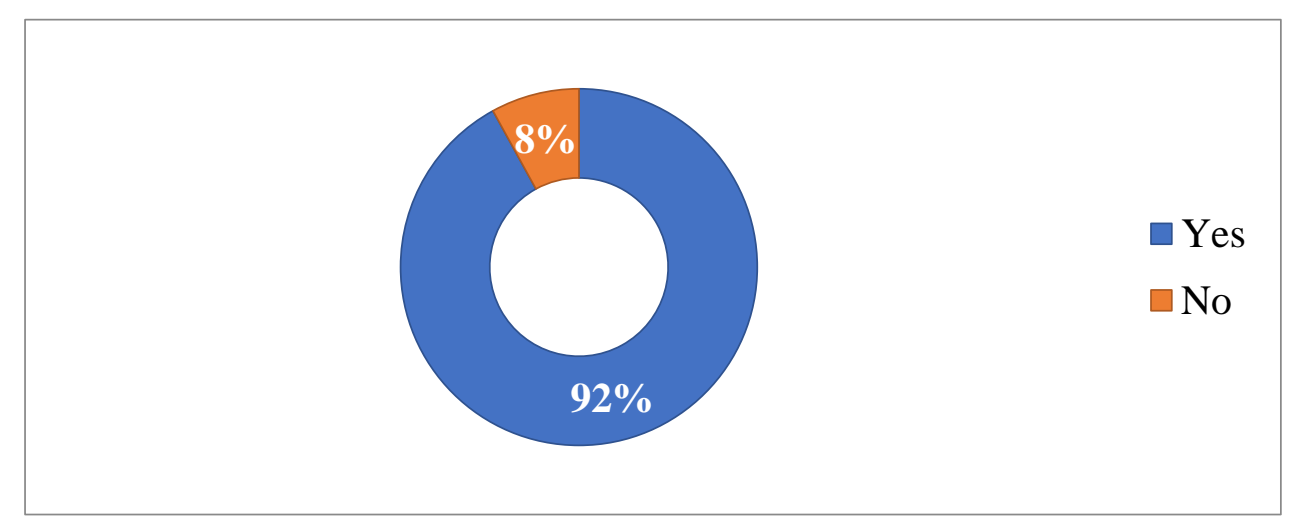

Figure 1: Knowledge about Digital Financial Services (DFSs) 
Among the total respondents, $92 \%$ know about digital financial services while $8 \%$ don't know about digital financial services yet. This indicates the financial literacy and awareness issue and also has relation with the matter of financial inclusion status in Bangladesh.

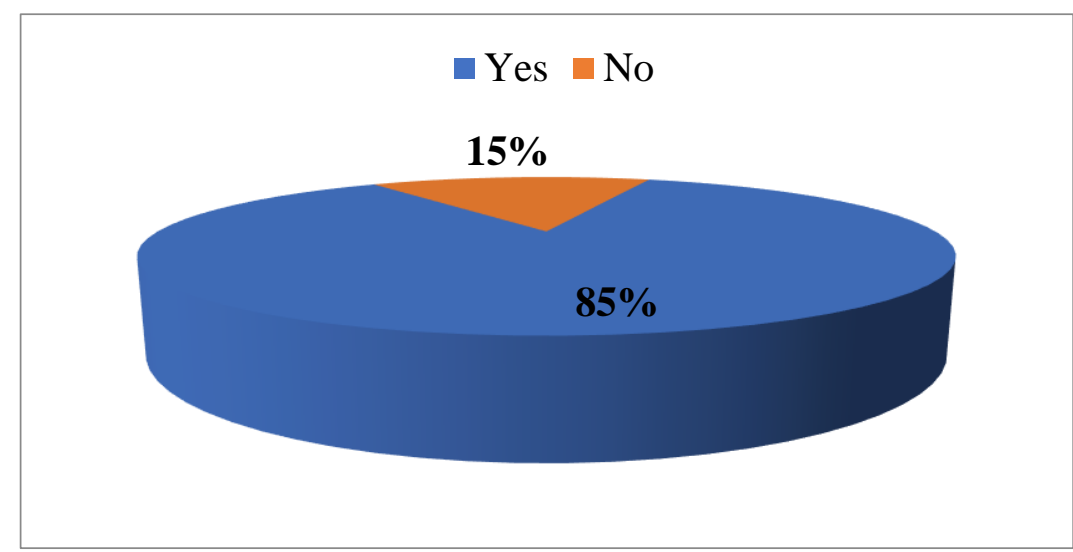

Figure 2: Use of DFSs for financial transaction

The respondents who know about DFSs and among them $85 \%$ use DFSs for day to day financial transactions and $15 \%$ do not use any of DFSs at all. Therefore, important indication of the survey result is that DFSs are popular in Bangladesh for completing financial transactions.

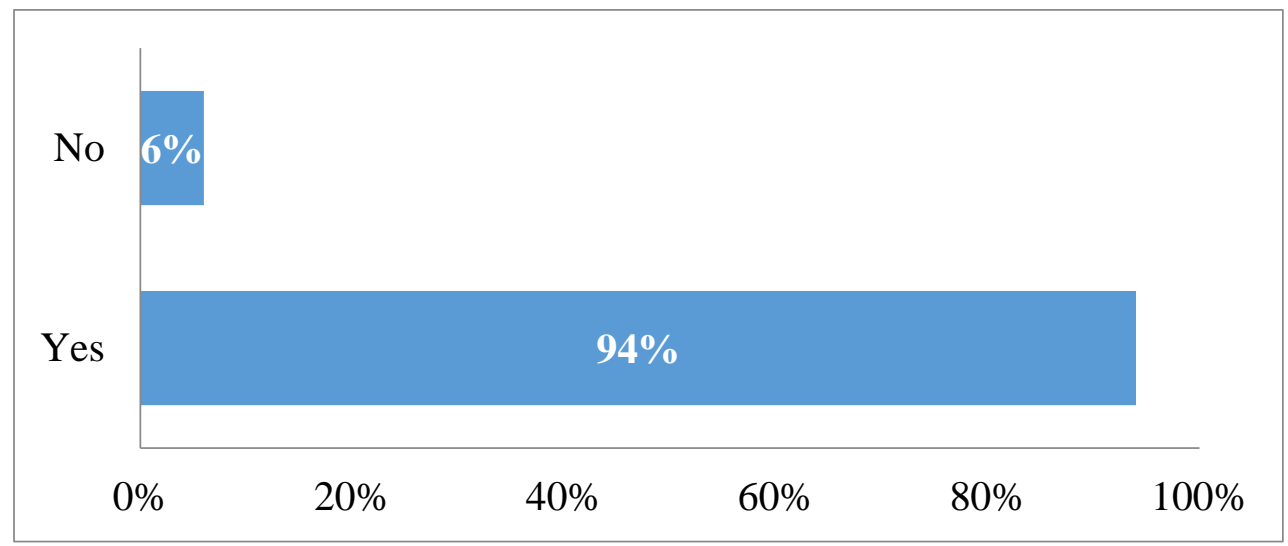

Figure 3: Effectiveness of DFSs during COVID-19 pandemic

During COVID-19 pandemic when normal life is being hampered regularly for health issue, DFSs have become the most risk free method of completing financial transactions. Again, the negative economic consequences have compelled many people to take emergency help and DFSs are playing a great role in this respect. According to our responses, we have found that $94 \%$ respondents think that DFSs are supportive on the COVID-19 pandemic. 


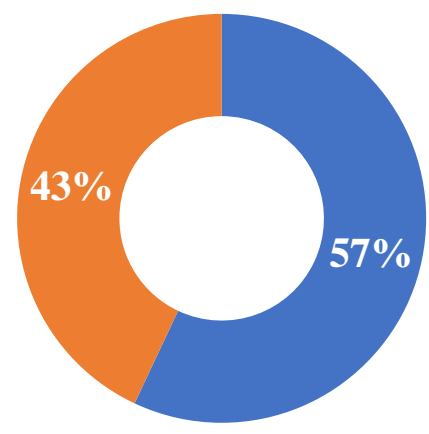

Yes

No

Figure 4: Risks of using banking channel for financial transactions during COVID-19 pandemic

There is a mix of opinion regarding whether it is risky of using banking channels for financial transactions during COVID-19 pandemic. 57\% of our respondents think that banking channel is risky while $43 \%$ still find banking channel as safe for transactions during the pandemic. It is therefore indicates the tendency of people to use banking channel for financial transactions from their habitual acceptance.

In another question of the survey, the respondents also have expressed their opinion on the reason behind the riskiness of banking transactions during the pandemic. Majority of the respondents think that difficulty in maintaining social distance is the reason behind the riskiness of banking transactions. Others have mentioned improper crowd management of the banks, customers' impatience and limited banking hour responsible for the risk of being infected in case of performing physical transactions in banks. Lastly, the human and hard money interactions also can be responsible on respondents' point of view for spreading the virus while transacting through banking channel during the pandemic.

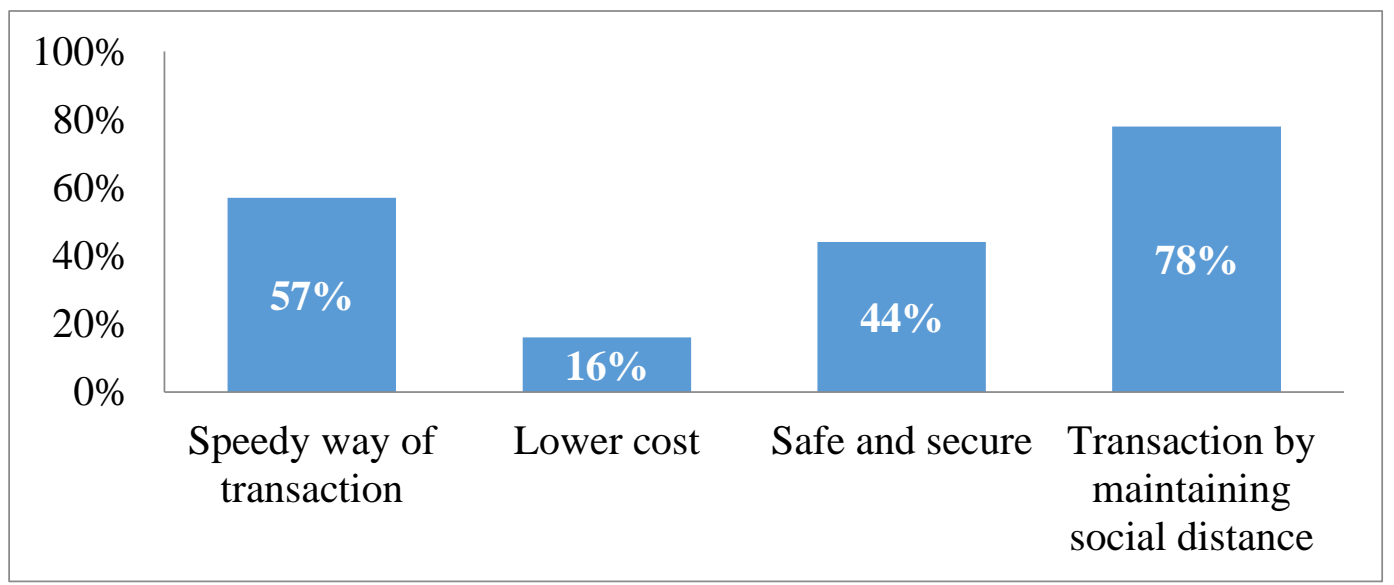

Figure 5: Ways in which DFSs are useful during COVID-19 
There may have many advantages of DFSs on Covid-19 crisis. For the analysis, we have identified four major probable advantages, they are: transaction by maintaining social distance, safety and security, cost-effectiveness and speedy method of transaction facility. We have mixed responses in this case as multiple options were available to be chosen by the respondents. Thus, $78 \%$ respondents think that DFSs are useful because transaction can be completed by maintaining social distance. $57 \%$ responses are supporting DFSs because they provide speedy way of transaction facility. $44 \%$ responses mention the safety and security procedure of DFSs to be useful during Covid-19 crisis. The cost advantage of DFSs is found less attractive to the respondents during Covid-19 crisis.

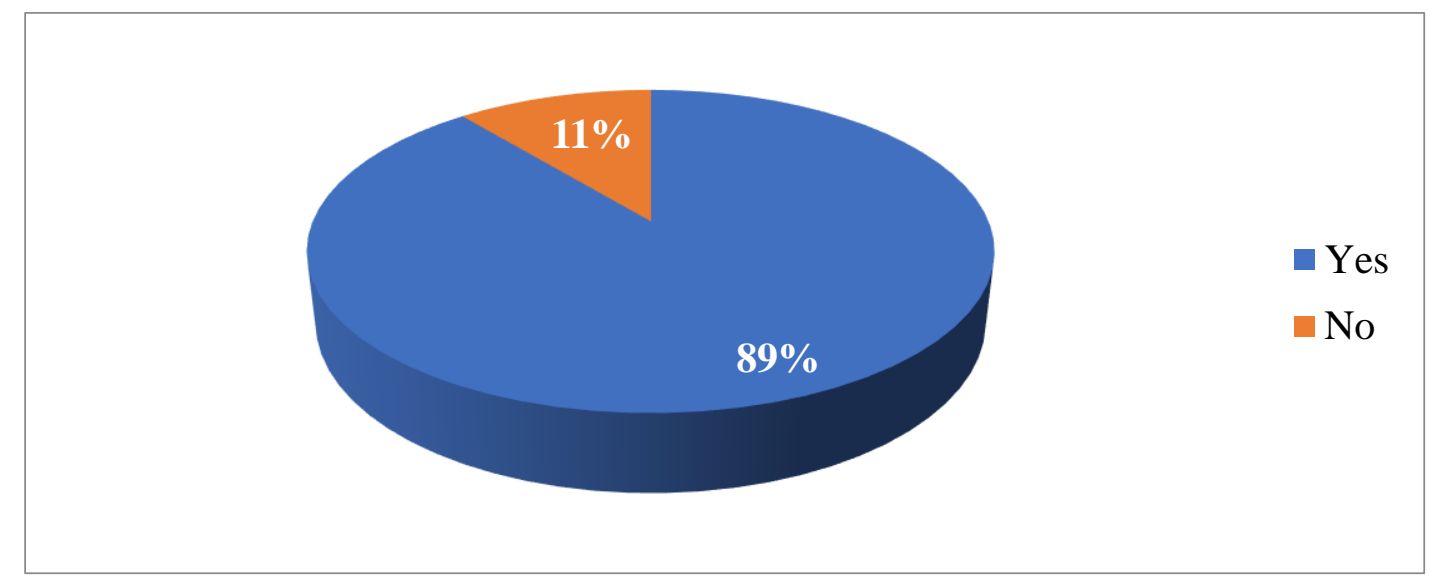

Figure 6: DFSs and ease of collecting remittance by Govt. during COVID-19 pandemic

For the developing country like Bangladesh, the collection of remittance plays a great role in keeping the economy strong and protecting the standard of living of people who are dependent on the remittance supply. During the COVID-19 crisis when the banking hours have become shorter and money transactions through banking channel have become risky, receiving the remittance money quickly is difficult without DFSs. From our 100 respondents, 88\% think that DFSs can help govt. to collect remittances at large scale.

\subsection{Reliability Analysis}

For our scaled data, we have conducted Reliability Analysis based on the survey responses. The purpose of this analysis is to ensure the internal consistency of the remaining Likert Scale questions of the survey. The following SPSS output tables exhibit the necessary explanations: 
Table 1: Case Processing Summary

\begin{tabular}{|c|c|c|c|}
\hline \multicolumn{2}{|c|}{} & $\mathbf{N}$ & \% \\
\hline \multirow{3}{*}{ Cases } & Valid & 100 & 100.0 \\
\cline { 2 - 4 } & Excluded $^{\mathrm{a}}$ & 0 & .0 \\
\cline { 2 - 4 } & Total & 100 & 100.0 \\
\hline
\end{tabular}

Source: Authors' Estimation

a. List wise deletion based on all variables in the procedure.

According to the case processing summary, there are no missing cases, which means, we have complete 100 responses for this analysis.

Table 2: Reliability Statistics

\begin{tabular}{|c|c|c|}
\hline Cronbach's Alpha & $\begin{array}{c}\text { Cronbach's Alpha Based on } \\
\text { Standardized Items }\end{array}$ & N of Items \\
\hline .639 & .643 & 4 \\
\hline
\end{tabular}

Source: Authors' Estimation

Table 2 provides the value for Cronbach's alpha. This is a measure of reliability of the data. According to the result, the Cronbach's alpha value is 0.639 which reflects the high reliability of the measuring instrument. Furthermore, it indicates that there is high level of internal consistency with respect to the specific sample.

Table 3: Item-Total Statistics

\begin{tabular}{|c|c|c|c|c|c|}
\hline & $\begin{array}{c}\text { Scale Mean } \\
\text { if Item } \\
\text { Deleted }\end{array}$ & $\begin{array}{c}\text { Scale } \\
\text { Variance if } \\
\text { Item Deleted }\end{array}$ & $\begin{array}{c}\text { Corrected } \\
\text { Item-Total } \\
\text { Correlation }\end{array}$ & $\begin{array}{c}\text { Squared } \\
\text { Multiple } \\
\text { Correlation }\end{array}$ & $\begin{array}{c}\text { Cronbach's } \\
\text { Alpha if } \\
\text { Item } \\
\text { Deleted }\end{array}$ \\
\hline $\begin{array}{c}\text { People's } \\
\text { dependence on } \\
\text { DFSs }\end{array}$ & 12.030 & 3.343 & .393 & .237 & .588 \\
\hline $\begin{array}{c}\text { DFSs help } \\
\text { NGOs private } \\
\text { donation }\end{array}$ & 12.020 & 3.091 & .465 & .267 & .538 \\
\hline $\begin{array}{c}\text { DFSs enable } \\
\text { govt. to reach } \\
\text { vulnerable } \\
\text { people }\end{array}$ & 11.930 & 2.854 & .548 & .374 & .474 \\
\hline $\begin{array}{c}\text { DFSs strengthen } \\
\text { accountability, } \\
\text { reliability and } \\
\text { transparency }\end{array}$ & 12.260 & 3.326 & .291 & .099 & .666 \\
\hline
\end{tabular}

Source: Authors' Estimation

The last column of table 3 presents the Cronbach's alpha value if item deleted from 
the scale. Here, the highest value is for the last item. This means that removal of any question, except question 4, it would result in a lower Cronbach's alpha. However, the removal of last question would result in small improvement in Cronbach's alpha. Again, the lowest (0.291) "corrected item-total correlation" value for this item might also come into consideration in this case.

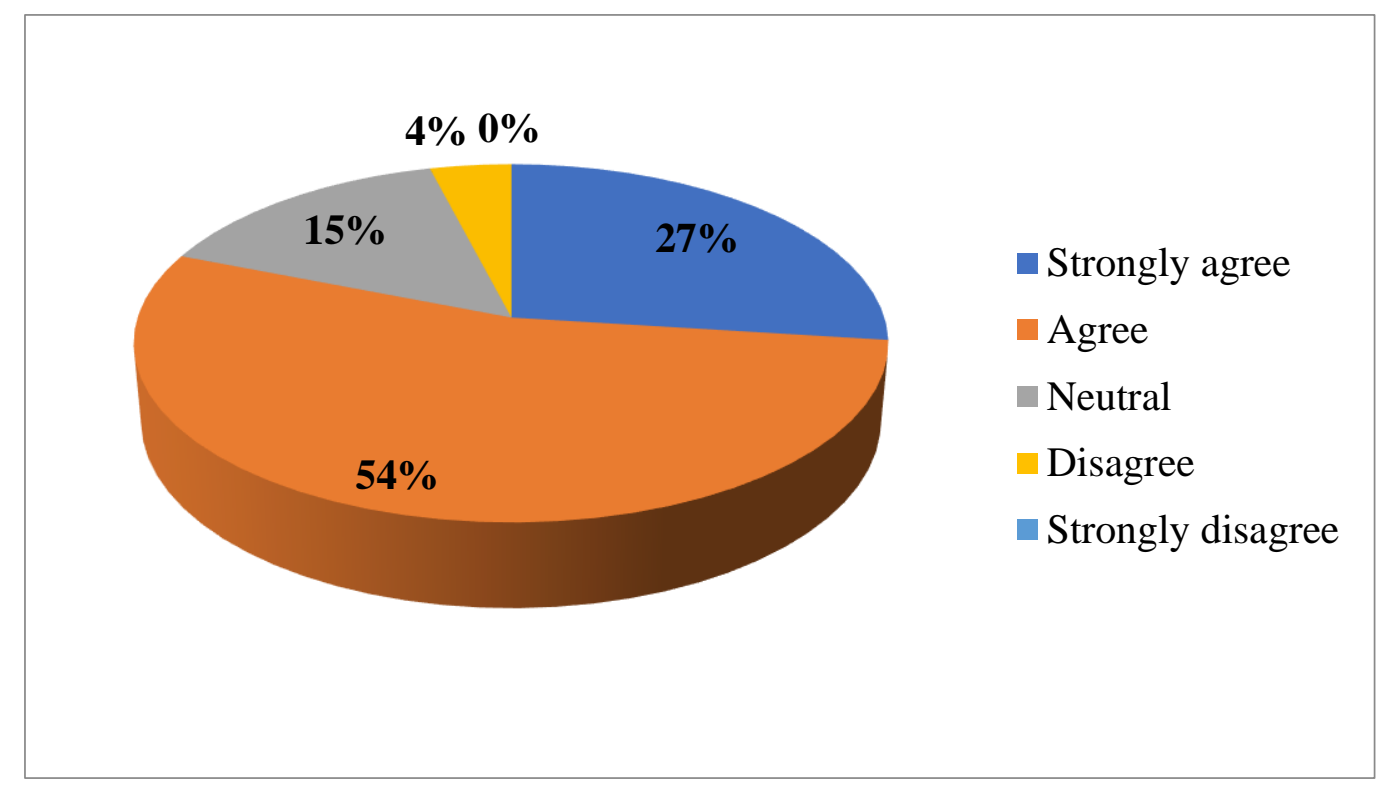

Figure 7: Dependency of people on DFSs for transaction during COVID-19

Dependency on DFSs for the financial transactions necessarily has increased during the pandemic for having the risks of being infected. Also, strict lockdown measure has increased the difficulty of moving to bank branches. Among the 100 respondents, $27 \%$ respondents have strongly agreed and 54\% have agreed with the statement of peoples' dependency on DFSs for transaction during COVID-19. Again, $15 \%$ of respondents have remained in neutral position while $4 \%$ have disagreed with the statement. 


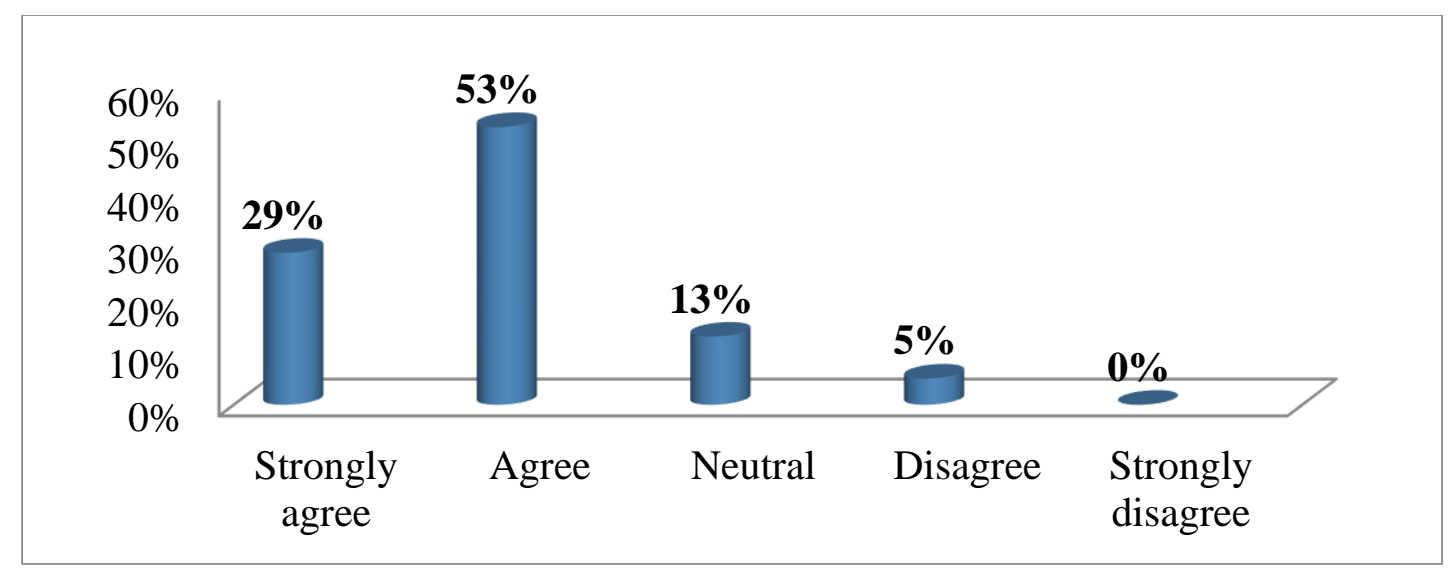

Figure 8: Support of DFSs to vulnerable people during COVID-19 pandemic through NGOs' and private donation program

To help the people during COVID-19 crisis, it is necessary to provide cash assistance to the vulnerable people. Therefore, DFSs can play a great role to accelerate the emergency responses by donor groups i.e. NGOs, private organizations and wealthy people. $29 \%$ of our respondents have strongly agreed and $53 \%$ have agreed with this statement. 5\% have disagreed with the statement while $13 \%$ of respondents have chosen neutral option in this respect.

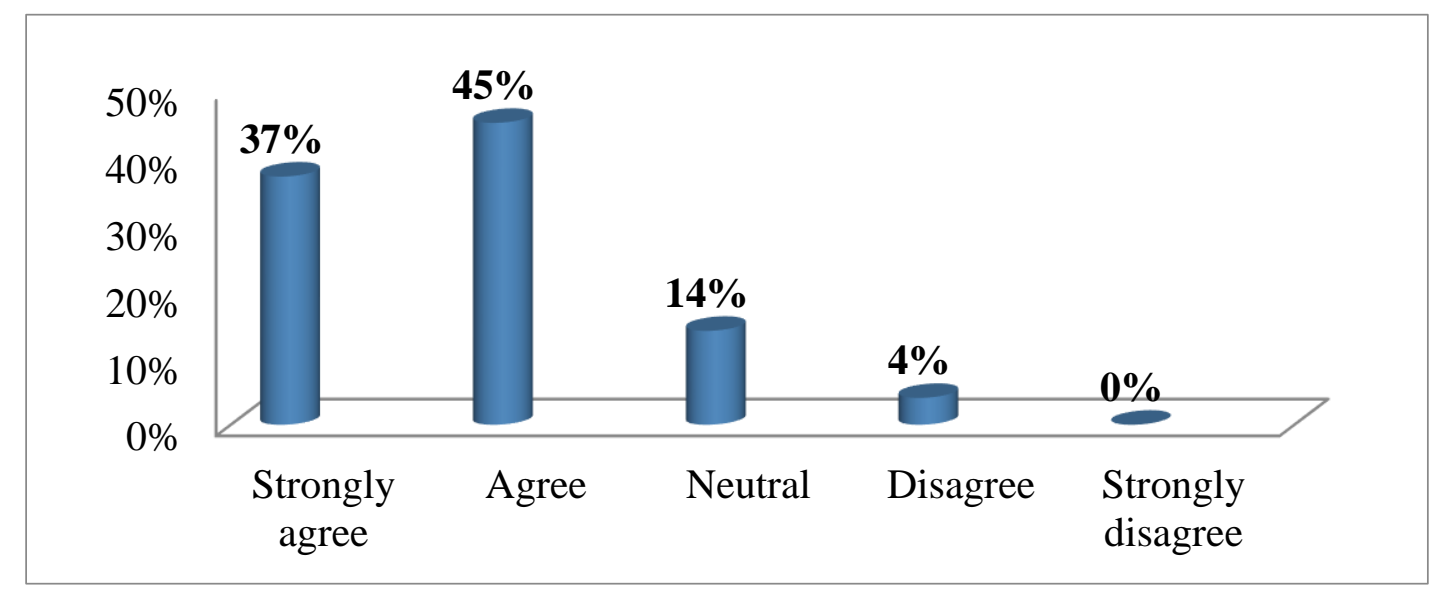

Figure 9: Enabling govt. to reach vulnerable people with financial assistance during the pandemic

Government has declared stimulus packages for the people who are facing difficulties in managing their livelihood during the crisis. As the transportation and movement around the country is unsafe for human interaction, it is necessary to provide cash assistance to victim people through digital financial means. Therefore, DFSs enable the Govt. to reach vulnerable people with financial assistance during 
the crisis. With this statement, we have $37 \%$ respondents who have strongly agreed and $45 \%$ have agreed. $4 \%$ of respondents have disagreed with the statement while $14 \%$ have chosen neutral position.

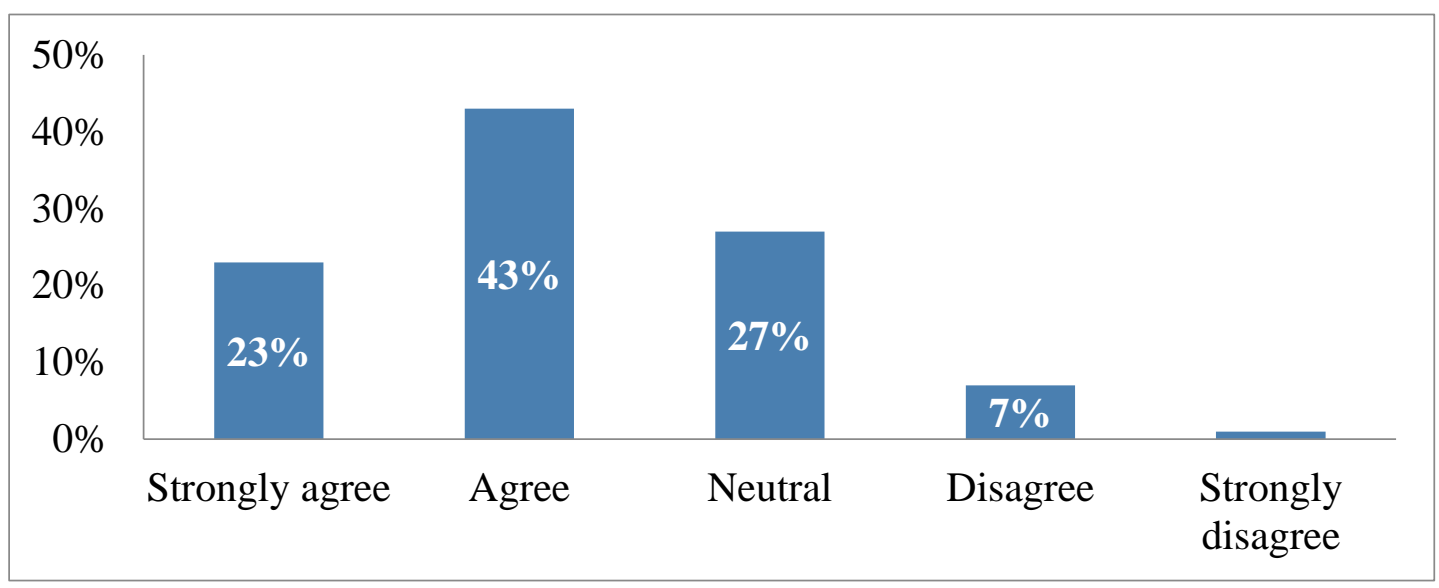

Figure 10: Strengthening accountability, reliability and transparency for government

Apart from the benefits of being the quickest, most cost effective and secure method of financial transactions, DFSs are reliable to the user as well. At the beginning of the crisis, the Government of Bangladesh declared huge amount of stimulus to be provided to the citizens and businesses. In this case, physical cash delivery is often not reliable and flexible in the bureaucratic context in Bangladesh. $43 \%$ of our respondents have agreed with the statement that DFSs can strengthen accountability, reliability and transparency for government in providing emergency funds to citizens and businesses. Here, $22 \%$ respondents have strongly agreed with the statement, $7 \%$ have disagreed and $27 \%$ have chosen neutral option.

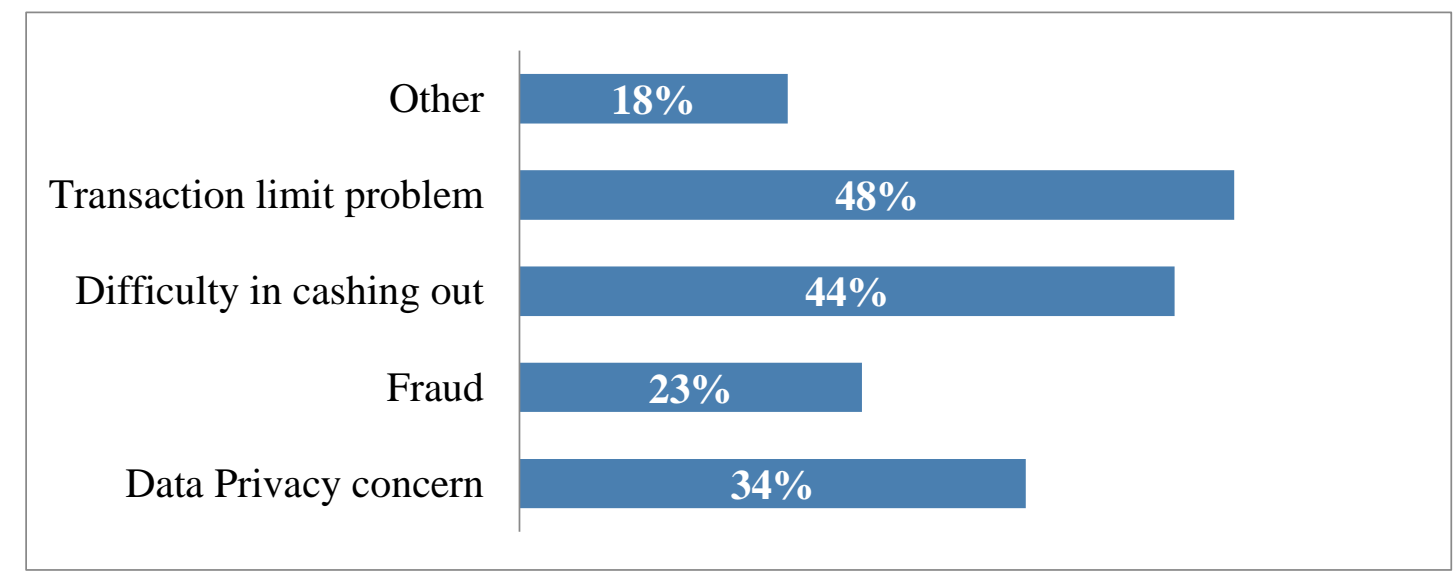

Figure 11: Challenges of using DFSs during Covid-19 
During the Covid-19 pandemic, DFSs are playing a strong role in helping the citizens performing financial transactions and receiving funds for financial difficulties. Here, we have identified four major challenges that the users may face during COVID-19 crisis. First one is data privacy concern, and we have 34\% respondents who think it as major challenge in using DFSs. Another challenge is availability of fund or fund withdrawing or receiving limit. This is a problem in case of crowd funding where there is a limit of money that can be sent, received or withdrawn in a day. We have maximum $48 \%$ responses on this point. Again, difficultly in cashing out or transaction via agents is a problem because of unavailability of agents for safety concern and strict lockdown declaration. We have $44 \%$ respondents supporting this point as a major challenge. Besides, $23 \%$ of respondents think that there is a scope of fraud in doing transactions through DFSs and it has increased during the pandemic. Moreover, $18 \%$ respondents think other unexplained problem as challenge that may directly or indirectly be linked to Covid19 pandemic.

\subsection{Discussion}

DFSs are experiencing a positive growth as for having a steady growth in Mobile Financial Services (MFSs) in Bangladesh. Among the MFSs, bKash has been considered as pioneer (Gomes, 2020). During the COVID-19 crisis, the adoption of e-wallet has accelerated as there has been a demand for contactless transactions everywhere. Urban consumers have made fast adoption of e-commerce and digital payments due to strict lockdown in place during the pandemic.

According to the data on 'Financial inclusion and digital financial statistics: Bangladesh Bank', total number of registered MFS accounts has reached more than 92 million. During the crisis, the digitized payments of private sector wages and utility bills have increased.

The following table shows total number of MFS account for the time period March to July 2020. This includes both urban and rural areas Also, the total transactions including salary disbursement, utility payments and other digital transactions (ATMs, POSs) are mentioned in the table. This indicates the extent of using DFSs and dependency of people on DFSs during the crisis situation prevailing in Bangladesh. 
Table 4: Extent of Using DFSs

\begin{tabular}{|c|c|c|c|c|c|c|c|}
\hline $\begin{array}{c}\text { Period } \\
\mathbf{2 0 2 0}\end{array}$ & \multicolumn{3}{|c|}{ MFS Total Account (Number) } & \multicolumn{2}{c|}{$\begin{array}{c}\text { MFS Transaction } \\
\text { (TK. Crore) }\end{array}$} & $\begin{array}{c}\text { Other } \\
\text { Digital } \\
\text { Transaction } \\
\text { (TK. Crore) }\end{array}$ \\
\hline & \multicolumn{2}{|c|}{} & \multicolumn{3}{|c|}{} \\
\hline & Urban & Rural & Total & Salary & Utility & Total & Total \\
\hline January & 30362199 & 50553328 & 80915527 & 1083.6 & 472.0 & 1555.6 & 17021.0 \\
\hline February & 30769206 & 51087390 & 81856596 & 1087.7 & 441.1 & 1528.8 & 16329.9 \\
\hline March & 31036064 & 51539686 & 82575750 & 1246.5 & 433.3 & 1679.8 & 16569.0 \\
\hline April & 32295863 & 52833204 & 85129067 & 1064.9 & 271.3 & 1336.2 & 8987.6 \\
\hline May & 32926055 & 55013279 & 87939334 & 2218.0 & 598.3 & 2816.3 & 12727.9 \\
\hline June & 33290589 & 55506486 & 88797075 & 2377.1 & 992.9 & 3370.0 & 13657.4 \\
\hline July & 34667086 & 57913182 & 92580268 & 4587.0 & 878.9 & 5465.9 & 19690.9 \\
\hline
\end{tabular}

Source: Financial inclusion and digital financial statistics: Bangladesh Bank

From this table, we can show the trend line of number of MFS account holders and the completion of digital transactions during the mentioned periods. We observe that the following figure (figure 12) shows a positive growth of MFS account opening in Bangladesh. In January the total number of accounts was 80.92 million and through a positive increase it has reached to 92.58 million in July.

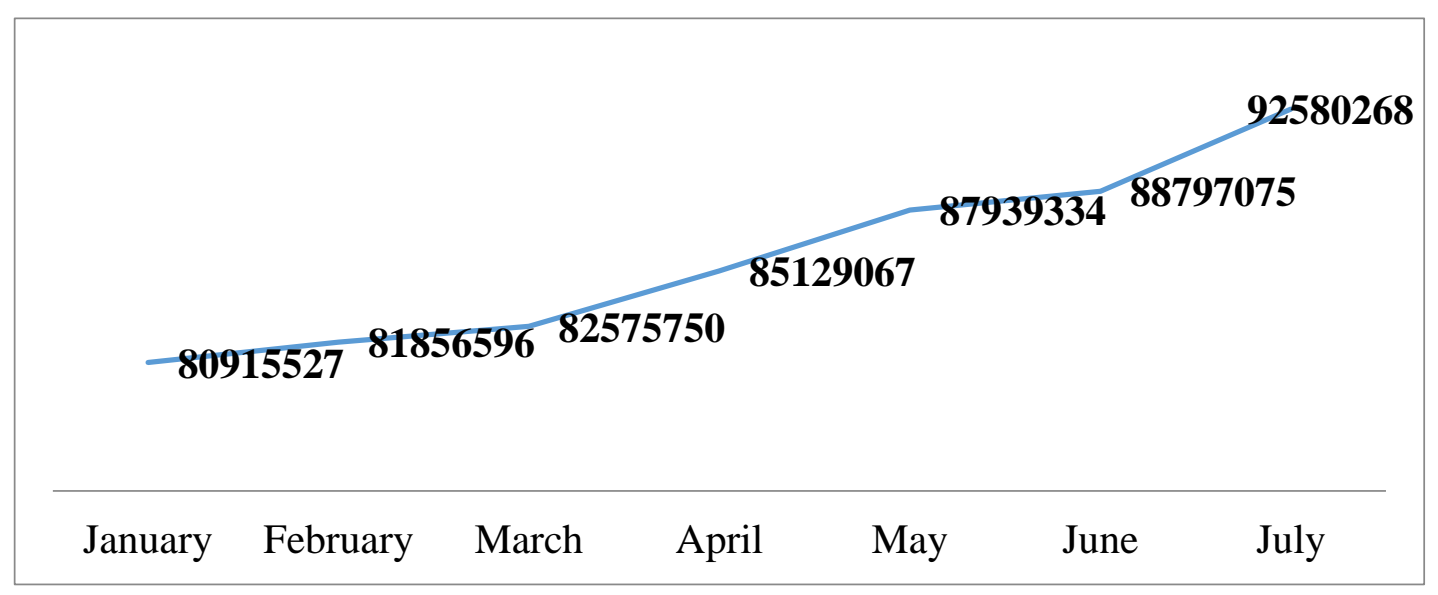

Figure 12: Trend of MFS Account Opening

Again, the following figure (figure 13) shows a trend line of MFS transaction amount (in crore taka). Through January to March the growth was almost flat and then a sharp decline in April because of economic uncertainty. From May, the amount has increased significantly and then continuing a positive growth till July. 


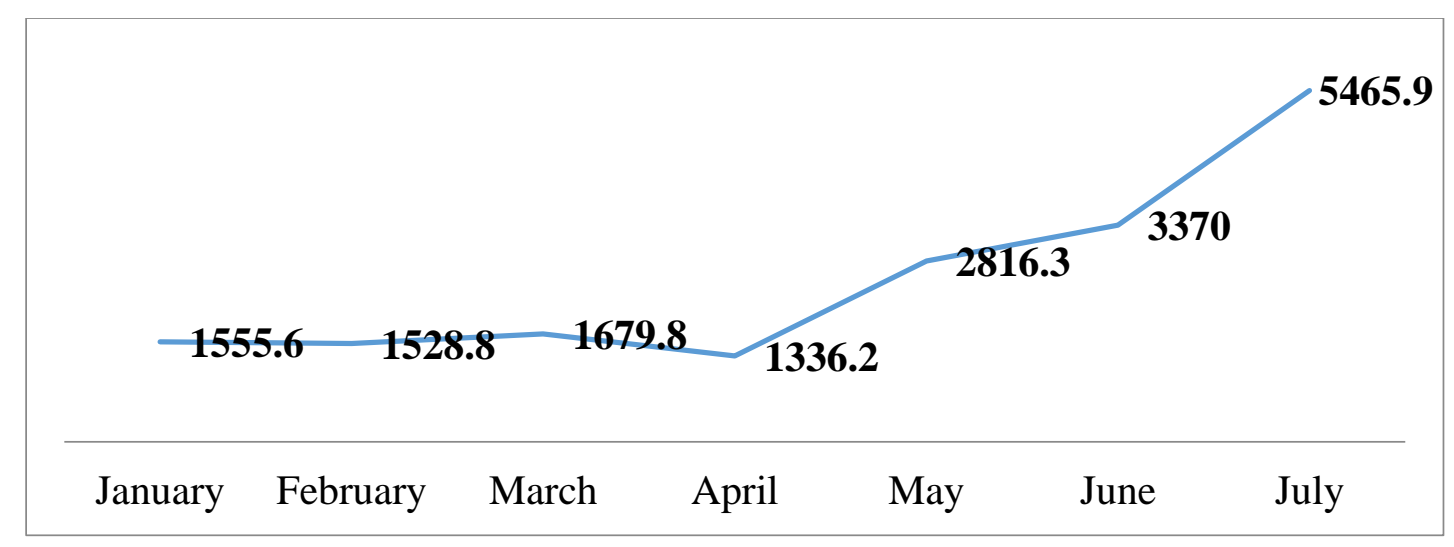

Figure 13: Trend of MFS Transaction Volume

Apart from the MFS transactions, DFSs also include the transactions through ATM, POS, CRM and e-commerce. In the following figure (figure 14), we also see an almost flat growth from January to March and then a significant decline in transactions in April for economic uncertainty. From the next month the transaction amount has increased significantly. Therefore, we see a positive growth trend till July.

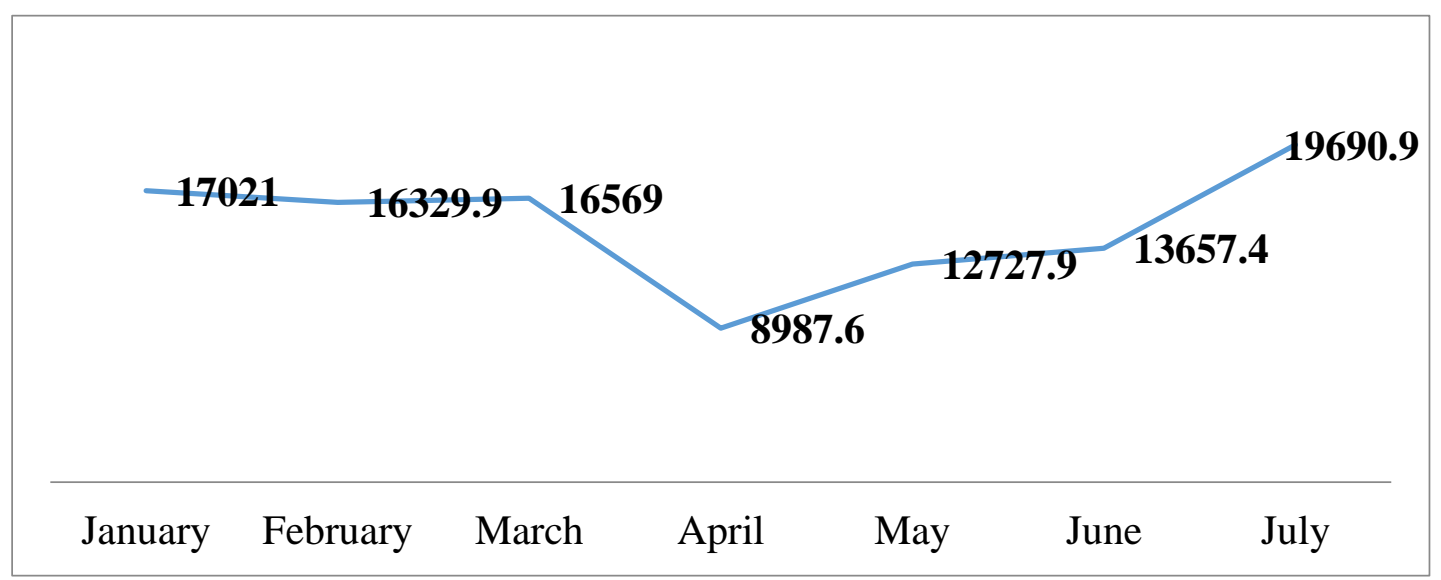

Figure 14: Trend of Transaction Volume through Other Digital Financial Means

The advantages of DFSs on COVID-19 crisis can be discussed on economic, social and individual point of view. First, DFSs are the most effective solution for the quickest response to face humanitarian emergencies. The cash based assistance which has initiated early or continuously initiating, can reach to the affected people immediately through MFS solutions. It is therefore just a need for 'cash in' to the desired mobile accounts. Again, the safety and security during the transaction can be maintained easily through DFS solutions. Except the fraud for less digital literacy 
among the rural population, the money transmission is the safest and most secure. In this case, the proof of the transaction is easy as SMS for confirmation is immediately sent to the receiver's mobile number. Thus, the stimulus package in the form of donation, salary distribution or for other uses can be deposited digitally without further difficulties. Besides, the cost is an issue where it can be both advantage and disadvantage to the users of DFSs. The cost can be considered as advantage in terms of 'opportunity cost'. Without using DFSs, the transactions are time-consuming and with the banking channel there are other costs related to transportation, waiting time in a line and sacrificing other important works to do. Thus, DFSs can be said as efficient method for both the victims and donors in facing the crisis situation due to the pandemic. Finally, the most important issue during the pandemic is 'social distancing'. It is necessary to complete the transaction while maintaining social distance. There are customer service points (agents) in almost every place around the country to complete the financial transactions for the clients. Thus, people in need of withdrawing, depositing or payment of money can easily complete the transaction while having less human interaction.

The collection of remittance is important for our country as it contributes a lot to our reserve which in turn help our economy to boost. During the pandemic, there has been a prediction that remittances may fall by $25 \%$ this year. However, unexpectedly the amount of remittance has stood $\$ 2599.56$ million in July, almost a $42 \%$ increase from the previous month ( $\$ 1832.63$ million). According to the economic experts, if the access to digital financial solutions can be improved, this will help in collection of remittances in great extent. Currently, international remittances can be sent in Bangladesh through enlisted and authorized Foreign Bank, Money Transfer Organization (MTO) and Money Exchange Houses to the recipient's bKash account. To encourage the senders, there is a $2 \%$ incentive facility on the received money from the Government. So, to prevent or to minimize the fall of remittance flow during the crisis periods, DFSs can play an effective role.

After a nationwide shutdown in 26 March, several stimulus packages were initiated by the Government. There has been a scheme to help 5 million vulnerable families through providing financial assistance of TK.2500. Under this scheme, TK. 12.50 billion has been announced and then placed to be distributed through mobile banking services ("Poor Families", 2020). Rupali Bank SureCash has been directly involved in disbursing TK. 2 billion among 8 lakhs beneficiaries. Besides, education stipends for graduate level students and 14 million primary level students have been decided to be distributed through mobile financial services ("Govt. Cash", 2020). DFSs also face different challenges during the pandemic in providing efficient customer services. The data privacy concern and digital fraud are the reason for depending on physical cash transactions by many people. The largest mobile financial operator bKash which have more than 40 million customer base is frequently asked to improve the security risk issue of the clients. During the pandemic, several forms of digital frauds have increased by taking the opportunity of the crisis situation. In this respect, regular advertising and awareness campaign have been communicated regarding data privacy and security to the users through 
mainstream and social media. Again, the social distancing measure has created challenges for DFS's operation during the pandemic. As people are more encouraged to do financial transaction while ensuring health safety, the demand for mobile money transactions has increased. These increasing demands have pushed challenges to digital financial service operators as they have to ensure the liquidity of e-money for the increased cash settlements. Limited banking hours and unavailability of field agents due to strict lockdown have hindered the operations of cash settlements in many cases. Furthermore, the existing transaction limit policy also has created challenge. For MFSs, the limit of 'cash in' transaction is only 5 in a day and monthly it is 25 . The limit range for 'cash in' amount is TK. 50 to TK. 30000 daily and TK. 200000 monthly. Per day 'send money' limit is 50 times and amount TK. 10 minimum and TK. 25000 maximum. There are limits for 'cash out' transaction which is maximum 5 times in a day and 20 times monthly. Maximum TK. 25000 can be withdrawn per day and TK. 150000 monthly from both agents and ATMs. Among the other challenges there is an arguable issue regarding the cost of transaction. For the 'cash out' transaction the users need to bear a significant cost which is TK. 18.50 for per TK. 1000 withdrawal. Recently, bKash has reduced the cost by TK. 3.50 if cash out is done through bKash app. Again, bKash tariff of TK. 5 for send money option has been criticized as it increases the cost for general as well as for donors in humanitarian purposes. Bangladesh Post Office's mobile financing service Nagad is trying to provide services for the lowest cost which is TK. 9.50 for a TK. 1,000 cash-out in a process of giving TK. 5 cash-back against each cash-in of TK. 1000. In respond to face the crisis situation, Nagad has decided to take necessary steps including cost minimization for the types of businessesessential goods, pharmacy, small and medium investors and post office transaction.

\section{Policy Implications}

DFSs are essential to bring the underprivileged people under broad financial accessibility. Considering the safety issue on amid fear of spreading the virus, adoption of digital financial solutions for financial transactions has increased. Moreover, for remittance collection and efficient implementation of disbursing stimulus packages from the Government, various mobile financial services including bKash, Nagad, Upay, SureCash and the likes are playing a significant role. Also, the donation from NGOs, private entities and individuals can reach the crisis affected populations by these digital financial means to help them meet their needs. In overall, this study has found that DFSs are useful and reliable tools in facing crisis during the pandemic. The study also has discussed on various challenges in this respect that need to be addressed properly by the authority. Therefore, the study suggests several policy guidelines to be considered for emphasizing the effective and efficient use of digital financial services to the vast majority of vulnerable population in confronting the crisis situation.

Microfinance Institutions (MFIs) can play a positive role in tackling probable economic downfall following the COVID-19 crisis. Therefore, an integration of 
DFSs with MFIs need to be explored that will surely help MFIs to access more unprivileged people in remote areas of the country. In addition, a common platform can be developed to widen the area of coverage of DFSs that will comprise the stateowned commercial banks, private banks and other institutions. The literacy program by Bangladesh Bank on financial and technology along with necessary awareness campaign should be accelerated to aware people about fraud arising from data privacy and security while using DFSs for financial transaction. Also, the charges for financial transactions through MFSs should be brought down significantly to make the services more affordable to the disadvantaged and vulnerable population during the crisis. There must be a level playing field for all the operators providing financial services in this respect. Finally, Necessary supports need to be extended and implemented from the Government that may include various direct or indirect incentives to boost the cashless economic activity in supporting the growth of the economy during the crisis.

\section{Conclusion}

It is undeniable to state that the COVID-19 pandemic has serious economic consequences on a developing country i.e., Bangladesh. The country is in challenge of facing negative shocks, supporting livelihoods and stimulating economic activity during COVID-19 crisis. In this response, the access to financial services is necessary in strengthening the resilience of populations. There is a strong message given by the coronavirus pandemic is that if we can embrace the digital financial tools, the economy will run under any circumstances.

This study mainly focused on how DFSs are helpful in confronting COVID-19 crisis in Bangladesh. Through analyzing the survey data and from overall discussion we can arrive at the conclusion that DFSs are advantageous in confronting COVID-19 crisis. DFSs can help in boosting economic activities and if the economy is well functioned during the crisis; the negative shocks will be automatically minimized. Therefore, the poor, disadvantaged and marginalized populations will face less vulnerability during the crisis.

However, there are further evidences need to be in place to better understand the use of and demand for financial services by different segments of crisis affected populations. Besides, we also need to evaluate the importance of sustained commitment of financial service providers to mitigate humanitarian emergencies. Moreover, the access to and use of financial services is complicated by legal, technical, social and policy barriers. Therefore, there is a scope of further research in terms of implementing and leveraging digital financial solutions as a tool to mitigate humanitarian crises situations.

ACKNOWLEDGEMENTS: This paper is considered as an honest effort to develop our practical and personal knowledge. We would like to express our profound gratitude and deepest regard to the honorable faculty Md. Tanvir Hamim, Assistant Professor, Department of Banking and Insurance, Faculty of Business 
Studies, University of Dhaka for his inspiring guidelines, valuable suggestion, constructive criticism and constant help throughout the preparation of this paper. We are also thankful to our family members and friends who offered encouragement, information, inspiration and assistance during the course of constructing this paper.

\section{References}

[1] Bangladesh Bnak. (2020). Financial Inclusion and Digital Financial Statistics. Retrieved from https://www.bb.org.bd/econdata/index.php.

[2] Bangladesh's stimulus package tops Tk 1.0 trillion. (2020, May 14). The Financial Express. Retrieved from https://thefinancialexpress.com.bd/economy/bangladesh/bangladeshsstimulus-package- tops-tk-10-trillion-1589443603.

[3] Davidovic, S., Prady, D., and Tourpe, H. (2020, June 22). You've Got Money: Mobile Payments Help People during the Pandemic. IMFBlog. Retrieved from https://central- banks.economicblogs.org/imfdirect/2020/blog-youve-moneymobile-payments-pandemic.

[4] Dewar, J. (2020, May 13). The Impact of the COVID-19 Pandemic on Financial Inclusion. The Finanser. Retrieved from https://thefinanser.com/2020/05/the-impact-of-the-covid-19-pandemic-onfinancial-inclusion.html.

[5] El-Zoghbi, M., Chehade, N., McConaghy, P., and Soursourian, M. (2017, April 12). The Role of Financial Services in Humanitarian Crises. CGAP. Retrieved from https://www.cgap.org/blog/series/financial-serviceshumanitarian-crises.

[6] Gomes, V. (2020, May 8). Mobile Financial Services soaring in a pandemicstricken Bangladesh. The Daily Star. Retrieved from https://www.thedailystar.net/toggle/news/mobile-financial-services-soaringpandemic-striken-bangladesh-1900507.

[7] Govt. cash gift for Corona-affected family disbursed through Rupali Bank SureCash. (2020, May 18). The Financial Express. Retrieved from https://thefinancialexpress.com.bd/economy/bangladesh/govt-cash-gift-forcorona-affected family- disbursed-through-rupali-bank-surecash1589741050 .

[8] Gurung, N. and Perlman, L. (2018). The Role of Digital Financial Services in Humanitarian Crises Responses. New York: Columbia Institute for TeleInformation. Retrieved from https://dfsobservatory.com/publication/focusnote-role-digital-financial-services-humanitarian-crises-responses.

[9] Hussain, Z. (2020, April 21). Cash transfer is the assistance the poor need right now. The Daily Star. Retrieved from https://www.thedailystar.net/business/news/cash-transfer-the-assistance- thepoor-need-right-now-1895119.

[10] K-Mujeri, M., and E-Azam, S. (2018). Role of Digital Financial Services in Promoting Inclusive Growth in Bangladesh: Challenges and Opportunities 
(InM Working Paper, No. 55). Dhaka: Institute for Inclusive Finance and Development. Retrieved from http://inm.org.bd/wpcontent/uploads/2018/06/Working-Paper-55.pdf.

[11] Poor families to get Tk.2500 cash assistance each. (2020, May 10), The Business Standard. Retrieved from https://tbsnews.net/coronaviruschronicle/COVID-19-bangladesh/50-lakh poor-families-get-tk2500-cashassistance-each.

\section{Appendix}

\section{A. Survey Questionnaire}

\section{Part 1: Demographic information}
a) Gender:
b) Age:
c) Education:
d) Profession:
e) District name:

\section{Part 2: General questions on DFSs}

i. Do you know about Digital financial services (DFSs)? 1)Yes. 2) No.

ii. Do you use any of DFSs for your financial transactions? 1) Yes. 2) No.

Part 3: Impact of Digital financial services (DFSs) in confronting COVID-19 crisis in Bangladesh

1. Do you find DFSs supportive during COVID-19 pandemic? 1) Yes. 2) No.

2. Is it risky of using banking channel for financial transactions during COVID19 pandemic? 1) Yes. 2) No.

3. If yes, how it is risky?

4. How DFSs are useful during COVID-19? a) Speedy way of transaction.

b) Lower cost. c) Safe and secure. d) Transaction while maintaining social distancing.

5. Do think DFSs support the Government to gain remittance at large extent during COVID-19 crisis? 1) Yes. 2) No.

6. People are dependent on DFSs for financial transaction during C0VID-19 1) Agree. 2) Strongly agree. 3) Neutral. 4) Disagree. 5) Strongly disagree.

7. DFSs help NGOs/private donors to provide financial support to vulnerable people during COVID-19.

a) Strongly agree. b) Agree. c) Neutral. d) Disagree. e) Strongly disagree. 
8. DFSs enable Govt. to reach vulnerable people with financial assistance during the pandemic when transportation and movement around the country is unsafe/restricted

a) Strongly agree. b) Agree. c) Neutral. d) Disagree. e) Strongly disagree.

9. DFSs can strengthen accountability, reliability and transparency for government in issuing emergency funds to citizens and businesses?

1) Agree. 2) Strongly agree. 3) Neutral. 4) Disagree. 5) Strongly disagree.

10. What are the challenges you have faced in case of using DFSs during COVID19? a) Data privacy concern. b) Fraud. c) Difficulty in cashing out. d) Transaction limit problem. e) Other. 